\title{
ELECTIONS TO THE PRINCIPAL EXECUTIVE COMMITTEE OF THE BRITISH DENTAL ASSOCIATION
}

Nominations are sought for the following regional seats on the Principal Executive Committee (PEC): Eastern, North West, Wales, West Midlands, and UK wide.

The PEC has overall responsibility for the control and direction of the policy and affairs of the BDA, and its members are the Directors of the Association.

There are 15 members of the PEC, including the senior officers. Starting in 2014, a third of the places on the PEC will be subject to annual election, with Eastern, North West, Wales, West Midlands, and one UK wide position, representing the first tranche of seats subject to this process.

The senior officers of the PEC are the Chair, Deputy Chair and the Chair of the Education, Ethics and the Dental Team Working Group. The other members of the PEC will have a fair share of overall responsibilities, and typically this will require:

- Attendance at all meetings of the PEC - around five a year, but maybe more when business demands

- Attendance at own country council meetings

- Attendance at UK Council meetings

- Sit on 1-2 sub committees/issue specific forums

- Attend general meetings of the Association.

It is anticipated that the approximate time commitment for a member of the PEC who is not a senior officer will be 20 days per year, with an annual remuneration of $£ 15,000$.

\section{Term of office}

This shall be until December 2017, with the entitlement to stand for a full three-year term of office at that point.

\section{Induction, support and training}

Membership of the PEC will carry significant organisational and legal responsibilities. There will therefore be a thorough induction programme for those elected, and ongoing training. Members will also have 'civil service' advice and support from the Chief Executive and his staff.

Next meetings of the PEC

Meetings of the PEC in 2015 are: 12 February, 30 April, 1 October, 9 December.

Nomination forms must be returned to the Elections Team at 64 Wimpole Street London W1G 8YS or elections@bda.org by 17.00 Friday 17 October 2014.

More information about the elections to the PEC and other BDA elections, including downloadable nomination forms, can be found at: www.bda.org/elections.

Hard copy election packs can also be obtained by contacting Stephen Skelton on 02075634141 or emailing s.skelton@bda.org.

\section{NEW GUIDANCE AIMS TO IMPROVE PRISONERS' ORAL HEALTH \\ A new guide has been launched which aims to help significantly improve the oral health of the prison population in Scotland. \\ The 'Mouth Matters' guide for train- ers aims to achieve better oral care for offenders and help address their oral health and psychosocial needs. It has risen out of research carried out in three Scottish prisons in 2011 by the University of Dundee's Dental Health Services Research Unit (DHSRU), NHS Forth Valley and the Scottish Prison Service. Professor Ruth Freeman, Co-Director of the DHSRU, said: 'Our survey showed that the oral health of Scottish prison- ers is poorer than that of the general \\ population. In addition, prisoners had an increased prevalence of physical and men- tal ill-health - with 11\% diagnosed with mixed anxiety-depressive states compared with $2.6 \%$ of the general population' \\ Derek Richards, Director of the Centre for Evidence Based Dentistry within the DHSRU, said: 'Good oral health helps our self-esteem, which is important for peo- ple trying to re-establish a place within the community' \\ It is hoped that the 'Mouth Matters' guidance will enable staff to be more confident in dealing with oral health matters, and help offenders to take the necessary steps towards better oral health.}

